\title{
La crisis en 140 caracteres: el discurso propagandístico en la red social Twitter ${ }^{*}$
}

\section{The crisis in 140 characters: propaganda discourse in the social network Twitter}

\author{
ANA MANCERA RUEDA \\ UNIVERSIDAD DE SEVILLA \\ UTA HELFRICH \\ UNIVERSIDAD DE GÖTTINGEN
}

Artículo recibido el / Article received: 30-10-2013

Artículo aceptado el / Article accepted: 11-03-2014

RESUMEN: El objetivo de este trabajo es el estudio de las representaciones de la crisis económica en el contexto español que pueden encontrarse en Twitter. Es esta una red social que permite una elevada presencia ciberespacial (Zhao y Rosson, 2009), de ahí que sea aprovechada por empresas, medios de comunicación, formaciones o líderes políticos y plataformas de reivindicación para difundir sus mensajes. Como trataremos de demostrar sirviéndonos del marco teórico sobre el discurso de la propaganda desarrollado por Charaudeau (2012), estas instancias enunciadoras recurren a etiquetas como \#crisis, \#austeridad, \#banca, \#escrache, \#stopdesahucios o \#paro para hacer que sus textos lleguen a un mayor número de internautas. Además, el análisis de un corpus formado por un total de 1.800 tuits en los que se incluyen hashtags que guardan relación directa con la situación de crisis en España nos ha permitido identificar distintas estrategias que apuntan a la existencia de una retórica de la persuasión en Twitter. Por último, identificamos los tipos de discurso propagandístico más frecuentes en relación con las etiquetas empleadas.

* La presente contribución se inscribe en el marco del Proyecto de Investigación FFI2011-23573, «Variación y adaptación en la interacción lingüística en español», financiado por el Ministerio Español de Ciencia e Innovación. Agradecemos a dos evaluadores anónimos de la revista Cultura, Lenguaje y Representación sus valiosas sugerencias. 
Palabras clave: propaganda, crisis económica, análisis del discurso, discurso mediado por ordenador, redes sociales, Twitter.

ABSTRACT: In this paper we analyse the (re)presentation of the economic crisis with special reference to Spain in messages on the electronic platform Twitter. As a social network, Twitter allows for an enormous cyberspace presence (Zhao and Rosson, 2009) and is therefore used as its preferred means of communication by companies, mass media, political parties and their leaders in order to spread their messages. By following the theoretical framework of propagandistic discourse developed by Charaudeau (2012), we will show why the use of hashtags such as \#crisis, \#austeridad, \#banca, \#escrache, \#stopdesahucios or \#paro guarantees accessing a wider number of cybernauts. Furthermore, the analysis of a corpus consisting of 1,800 tweets containing such hashtags can be taken as evidence for the existence of a rhetoric of persuasion on the electronic platform Twitter. Finally, we have identified the most common types of propaganda speech in relation to the hashtag used.

Keywords: propaganda, economic crisis, discourse linguistics, computer mediated communication, social networks, Twitter.

\section{Introducción}

Por su omnipresencia y actualidad temática, Twitter puede caracterizarse como el sismógrafo del mundo moderno. Es esta una plataforma en línea que ofrece la posibilidad de enviar y publicar mensajes de hasta un total de 140 caracteres desde un sitio web, o por medio de SMS, mensajería instantánea y aplicaciones creadas ad hoc para móviles. Es decir, constituye lo que se denomina una red de microblogging o nanoblogging, pues de forma similar a las bitácoras -aunque en un espacio mucho más restringido-, permite crear contenidos que, al tiempo que se muestran en la página del perfil del usuario, son difundidos de manera inmediata a otros internautas que han elegido la opción de recibirlos. De ahí que Twitter suela identificarse también como una red social ya que, al igual que sucede en Facebook o LinkedIn, se basa en la creación de un perfil susceptible de actualizarse periódicamente mediante el envío de mensajes que el emisor puede mostrar públicamente o restringir a miembros de su círculo de amigos.

En este trabajo abordamos el análisis de algunas de las numerosas representaciones de la crisis económica global que pueden encontrarse en Twitter. 
Si bien, por la amplitud del corpus disponible, hemos decidido acotar nuestro trabajo al contexto español. Para ello nos centramos en el estudio de diversos hashtags que han llegado a convertirse en trending topic en España. Orihuela (2011: 34) define el hashtag o 'etiqueta' como una palabra clave que, precedida del signo de la almohadilla (\#), sirve para identificar el tema de un mensaje. ${ }^{1}$ Cuando esta es utilizada de manera recurrente en un gran número de tuits durante las últimas horas puede llegar a convertirse en trending topic, es decir, en 'tema del momento' en un determinado país, o en una ciudad concreta.

En realidad, el uso de las etiquetas no es exclusivo de Twitter, sino que existen otras plataformas de comunicación digitales que también las utilizan. De hecho, como explica Menna (2012: 37), la almohadilla fue empleada por primera vez con una intencionalidad similar a aquella con la que hoy se usa en Twitter en los chats, donde servía para identificar canales y temas de carácter global -frente a aquellos de alcance local, que se marcaban con el símbolo \&-. Actualmente, en la Web 2.0 los usuarios se sirven del signo \# para indicar metadatos, es decir, elementos capaces de proporcionar información adicional a un mensaje, facilitando así su clasificación. Para Zappavigna (2011), en Twitter el hashtag extiende el significado potencial de un mensaje, permitiendo la creación de un ambiente de afiliación entre aquellos usuarios que «conversan» sobre un mismo tema. ${ }^{2}$ Por tanto, además de como hiperenlace interactivo, actúa también como mecanismo de búsqueda, ya que la recopilación de todos los tuits que poseen una misma etiqueta permite consultar la miríada de contenidos y opiniones generadas en torno a un determinado asunto. Esto hace que puedan otorgársele funciones discursivas que analizaremos en este trabajo desde una perspectiva pragmalingüística.

\section{Metodología}

\subsection{Corpus y procedimiento}

Para llevar a cabo nuestro estudio hemos recopilado un corpus de 1.800 tuits publicados entre mayo de 2012 y octubre de 2013 en los que se incluye,

1. Cfr. también la caracterización de las etiquetas y los consejos para utilizarlas correctamente ofrecidos por el Centro de Ayudas de Twitter: <https://support.twitter.com/articles/247830que-son-las-etiquetas-simbolos\#>. Última consulta: 26-10-2013.

2. Como explica la propia investigadora: «[...] the hashtag, a typographic convention on Twitter, has extended its meaning potential to operate as a linguistic marker referencing the target of appraisal in a tweet» (Zappavigna, 2011: 1). 
al menos, alguna de las principales etiquetas que guardan relación directa con la crisis económica en España. Entre ellas hemos seleccionado las siguientes, por encontrarse entre las que se utilizan de manera más recurrente, lo que las ha llevado a convertirse en trending topic nacional en reiteradas ocasiones: \#austeridad, \#banca, \#crisis, \#crisiseconomica, \#desahucios, \#economistasfrentealacrisis, \#EPA, \#escrache, ${ }^{3}$ \#euco, \#Eurogrupo, \#pah, \#paro, \#pensiones, \#recapitalización, \#recesión, \#rescates, \#stopdesahucios y \#15M. Es preciso advertir que el objetivo de nuestro trabajo no radica en contabilizar el número total de tuits que hacen uso de una u otra etiqueta pues, dada la actualización constante de esta red social, tal porcentaje se encuentra sometido a variación diaria. Por ejemplo, en el momento de llevar a cabo esta investigación, el número de mensajes que contenían la etiqueta \#stopdesahucios era de 144. Sin embargo, durante la revisión de este artículo para su publicación tres meses después pudimos comprobar que esta cifra prácticamente se había triplicado. Dado que estas fluctuaciones considerables del número de tuits por hashtag se encuentran motivadas por la actualidad noticiosa, hemos considerado de mayor interés para la investigación que presentamos a continuación ofrecer una muestra homogénea de las dieciocho etiquetas mencionadas más arriba. De ahí que el corpus analítico se encuentre conformado por una selección de cien tuits por cada hashtag.

La significación excesivamente amplia del término crisis hace que bajo este marbete se incluyan mensajes que abordan contenidos tan variopintos como la crisis del biodiésel o la acontecida en Venezuela tras la muerte de su presidente Hugo Chávez. Sin embargo, hemos analizado exclusivamente aquellos textos que tienen una vinculación estrecha con la situación económica española. Así, en muchos de ellos los usuarios de Twitter comparten con sus seguidores noticias que confirman que el país continúa en recesión,

Borja_Colón((@borjacolon).El Nobel de economía Joseph E. Stiglitz recuerda que «un país con $25 \%$ de paro sigue en \#recesión» http://bit.ly/17kgHq4 \#crisis. 08-10-2013. Tuit. $^{4}$

3. De acuerdo con el Diccionario de americanismos (Asociación de Academias de la Lengua Española, 2010) el escrache es una «manifestación popular de denuncia contra una persona pública a la que se acusa de haber cometido delitos graves o actos de corrupción y que, en general, se realiza frente a su domicilio o en algún otro lugar público al que deba concurrir la persona denunciada». Cfr. «Escrache y escrachar, términos adecuados», Fundéu, 27-032013, disponible en: $<\mathrm{http} / / \mathrm{www}$.fundeu.es/recomendacion/escrache-y-escrachar-terminosadecuados/>. Última consulta: 26-10-2013.

4. Seguimos aquí el formato propuesto por la Modern Language Association (MLA) para la citación de tuits. Además, reproducimos todos los tuits tal y como fueron publicados, sin 
y libros que tratan de explicar el origen de esta:

Jesús Larená(@JMLarena).Leo \#DiariodelCrasch del profesor@sninobecerra y entonces comprendo como hemos llegado a donde estamos, y como lo avisó \#crisis. 09-10-2013. Tuit.

Además, algunos se sirven de la segunda persona del singular con valor impersonal para comentar lo que parece ser una vivencia personal,

José María Carmonał(@JoseMCarmona).La \#crisis le empieza a pasar factura a la educación de muchos. Ahora te saludan o no dependiendo de tu situación laboral. 15-10-2013. Tuit.

o manifiestan su asombro ante la bajada de los precios en la hostelería con el fin de incentivar el consumo:

Dani G. C.7(@DaniGCorvo). Nunca pensé que se podía comer tan barato fuera de casa. Hoy he visto hamburguesa de $1 €$ para dos con dos vasos de agua \#crisis. 08-10-2013. Tuit.

Mientras que otros internautas recurren a esa misma etiqueta precisamente para poner en duda la existencia de la crisis:

Paco Vázquez†(@pakvazquez). Vale sí, está muy bien pero no estábamos en crisis? En Málaga esta oferta se agotó el mismo día que salió... \#crisis pic. twitter.com/K7aumpQH4s. 08-10-2013. Tuit.

También el sintagma nominal fusionado para constituir el hashtag \#crisiseconomica se encuentra en mensajes que dan cuenta de sus consecuencias en distintos países, como Estados Unidos, Japón, México o Venezuela. Sin embargo, nos centraremos aquí únicamente en el estudio de aquellos que, por ejemplo, tratan de explicar las medidas puestas en práctica por el Eurogrupo para hacer frente a los problemas de la banca española,

Alejandro Pacheco 7(@Ale_Pacheco). El Eurogrupo cree innecesario prorrogar el programa de rescate de la banca española http://adf.ly/XXkVq \#Crisiseconómica @Ale_Pacheco. 15-10-2013. Tuit.

omitir los errores ortográficos ni aquellas otras muestras representativas del subcódigo escrito que está difundiéndose en Internet. 
o en los que difunden informes de organismos internacionales que tienen que ver con las previsiones económicas de España:

Generacionceró (@generacion0cmnt). El FMI asume que España cumplirá el objetivo de déficit en 2014 http://ow.ly/pDiWG \#crisiseconomica \#generacion0cmnt. 08-10-2013. Tuit.

Incluso hay internautas que exploran desde su ámbito profesional las consecuencias que la crisis puede tener en la población:

Psic. Covarrubias 1(@covarrubitas). La persistencia de preocupaciones económicas reduce las capacidades cognitivas - http://goo.gl/Oy1H3d \#CrisisEconómica. 10-10-2013. Tuit.

Esto ha hecho que adquieran una enorme difusión en esta red social un conjunto de artículos y monografías elaboradas por economistas para tratar de explicar las principales causas de la recesión, o con el fin de proponer medidas que puedan ayudar a hacer disminuir sus efectos, lo que ha dado lugar a la etiqueta \#economistasfrentealacrisis:

Jaime Bravo †(@JaimeMAD). Mañana sale mi artículo «Los peligros de la desregulación»publicado en @MadridEco \#economistasfrentealacrisis. 25-122012. Tuit.

Algunas instituciones recurren también a la etiqueta \#factordesostenibilidad para difundir información de carácter especializado que pueda interesar a aquellos internautas que deseen saber, por ejemplo, cómo se calcula el porcentaje de los presupuestos generales destinados a las pensiones en diversos países europeos,

InstitutoAvivá(@InstitutoAviva).Consultacómoseaplicael\#Factordesostenibilidad en otros países europeos http://bit.ly/REUjVm. 18-06-2013. Tuit.

proporcionando incluso enlaces que les permitirán descargar documentos como el informe elaborado por un comité de expertos para asesorar al Gobierno español sobre la reforma de las pensiones:

Pablo Sanjuán Garcíał(@pasangar). El comité de expertos entrega el informe http://www.lexdiario.es/noticias/200524/informe-del-comite-de-expertossobre-el-factor-de-sostenibilidad-del-sistema-publico-de-pensiones 
sobre el \#factordesostenibilidad de las \#pensiones http://www.lexdiario.es/ noticias/200526/el-comite-de-expertos-entrega-el-informe-sobre-el-factor-desostenibilidad-de-las-pensiones... 10-06-2013. Tuit.

Véase cómo en el mensaje anterior se hace uso tanto de la etiqueta \#pensiones como de la de \#factordesostenibilidad, que identifica la temática del tuit de manera más precisa, pues este informa sobre la propuesta de modificar el factor mencionado para calcular cómo se han de pagar las pensiones del sistema de la Seguridad Social a partir de 2014.

Según puede apreciarse en su estructura morfológica y su contenido semántico -tanto individual como en conjunto-, 5 las etiquetas contribuyen a la conformación ideológica del concepto de crisis. Así, a través de ellas los actores discursivos manifiestan su perspectiva enunciativa. Por ejemplo, hashtags como \#paro o \#desahucios poseen connotaciones negativas. En especial la lexía de carácter polisémico desahucio, que en los mensajes que pueden encontrarse en nuestro corpus adquieren un valor emocional que trasciende el significado del término jurídico. ${ }^{6}$ Por otra parte, desde un punto de vista pragmático, determinadas etiquetas como \#Eurogrupo, \#euco o \#banca suelen adquirir en los tuits analizados carácter peyorativo, al ser utilizadas para hacer alusión a aquellos a los que se atribuye la responsabilidad de la crisis económica. Por el contrario, \#stopdesahucios, \#pah, \#15M y \#escrache actúan como eslóganes propagandísticos, símbolos de la lucha contra los efectos de la crisis y sus causantes. Además, con ellas los autores de estos tuits incitan a la acción. A veces de manera implícita, como puede interpretarse en el hashtag \#escrache, o incluso de forma explícita mediante una estructura morfológica apelativa, como en \#stopdesahucios.

Por otra parte, con frecuencia las etiquetas no se sitúan en una posición marginal, sino que se integran en el mensaje como un sintagma nominal más en el que sus lexías pueden presentarse fusionadas:

5. Así, con frecuencia se incluye en un tuit más de un hashtag, y al ser combinados y retuiteados estos se reúnen en el mundo virtual y llegan a formar una superestructura semántica y temática en la conciencia colectiva, que contribuye también a determinar el campo conceptual del término crisis. De forma que al combinar distintas etiquetas se refuerzan además tanto el efecto de actualidad como el de interconexión, llegando a vincular varias comunidades de interés (community building).

6. Cfr. el Diccionario de la Lengua Española (Real Academia Española, 2001), que en su primera acepción define el verbo desahuciar como: «Quitar a alguien toda esperanza de conseguir lo que desea». Disponible en: <http://lema.rae.es/drae/?val=desahucio>. Última consulta: 2710-2013. 
PedroLázaroGómará(@plazaro67).Losexpertosproponenq\#factordesostenibilidad entre en vigor entre 2014 y 2019 pero q no se bajen nominalmente las \#pensiones actuales. 07-06-2013. Tuit.

Si bien esto no siempre ocurre, como demuestra el siguiente texto con el que la periodista Susanna Griso pretende dar a conocer ante una audiencia potencial uno de los contenidos que se abordarán en su programa de televisión:

SusannaGrisó (@susannagriso). El gobernador del Banco de España recomienda planes de pensiones privados. El gobierno los estimulará. Hoy en (a)EspejoPublico. \#pensiones. 20-06-2013. Tuit.

Adviértase cómo, en los casos en los que la etiqueta aparece al final del mensaje, es decir, sin integración sintáctica alguna, permite que esta sea visualizada de manera más rápida, y al mismo tiempo resume a modo de eslogan el contenido del tuit. Y es que muchos de estos hashtags persiguen una finalidad fundamentalmente propagandística, como trataremos de demostrar a continuación.

\subsection{Marco analítico}

Para el análisis de los tipos de discurso propagandístico que pueden encontrarse en los tuits recopilados nos apoyamos en primer lugar en el marco teórico desarrollado por Charaudeau (2012: 127). De acuerdo con este investigador, el discurso propagandístico es aquel que «incita a hacer» y que se caracteriza por la posición de autoridad que adopta el locutor, por su voluntariedad, por el hecho de que la meta se constituya siempre en una instancia colectiva, y por el doble esquema cognitivo según el cual se organiza. Este tipo de discurso puede localizarse en nuestro corpus, donde encontramos numerosos mensajes en los que se pone en práctica una estrategia para ubicar al alocutario en posición de «deber creer». Por ejemplo, con el siguiente texto la Asociación de Usuarios de Bancos, Cajas y Seguros insta a los usuarios de Twitter a aprender de sus consejos para llevar a cabo un consumo responsable que les permita ahorrar dinero:

ADICAEt(@ADICAE). Mira y aprende cómo un consumidor responsable gana 450 euros eligiendo bien dónde pone su \#dinero: http://ow.ly/kGbWc \#banca. 03-05-2013. Tuit. 
$\mathrm{Su}$ asesoramiento se presenta por tanto como esencial para lograr uno de los principales fines perseguidos por los ciudadanos en momentos de crisis, que no es otro que el de economizar en las compras.

Otro de los rasgos definitorios del discurso de la propaganda es su intencionalidad, que hace que el locutor pueda ser responsabilizado de las acciones que promueve con su enunciación. Así, de ser cierto que el número de teléfono que se recoge en el siguiente mensaje pertenece realmente al presidente del Banco Santander, los autores de este tuit podrían ser detenidos:

Anonymous Action(@AnonymousAction).¿Qué tal si le acosamos telefónicamente como hacen ellos con nosotros? Emilio Botín TELF: 942271352 http://www. anonpaste.me/anonpaste2/index.php?44d479bcffa040ec\#hj7CG9yHnLyPbLzD1s eqTvg1g6XWaK9sMUlafVvj738= ...\#Escrache. 29-04-2013. Tuit.

Y es que la revelación de información personal sobre un sujeto de relevancia pública a través de las redes sociales es un delito tipificado en el Código Penal español que ha llevado ya a la cárcel a algunos usuarios de Twitter. ${ }^{7}$ Tal vez por eso los responsables de este mensaje se escondan tras un seudónimo utilizado en todo el mundo por diferentes grupos, con el fin de realizar en su nombre acciones de protesta. En este caso, los gestores del perfil@AnonymousAction se sirven del espacio público de carácter virtual que genera la etiqueta \#escrache entre aquellos internautas que la siguen, para constituir una instancia de recepción colectiva, tratando de esta forma de que su incitación al acoso del conocido banquero tenga acogida entre un mayor número de personas.

Por último, el discurso propagandístico se caracteriza por su doble condición de producto narrativo y argumentativo. La narración permite seducir al alocutario sin que este sienta que se le está sometiendo a ningún tipo de exigencia, mientras que el objetivo de la argumentación no es otro que el de persuadirlo imponiéndole un modo de razonamiento que invalide las posibles objeciones respecto al esquema narrativo. Dada la limitada extensión de un tuit, creemos que la dimensión narrativa solo puede identificarse en el conjunto de los mensajes de un perfil que comparten un mismo referente. Por ejemplo, desde la

7. Cfr. por ejemplo la siguiente noticia: «Detenido por difundir en Twitter datos personales de Rosa Díez y Tony Cantó», El Correo, 17-05-2013, disponible en: <http://www.elcorreo.com/ vizcaya/20130517/mas-actualidad/politica/detenido-difundir-twitter-datos-201305171115. html>. Última consulta: 20-10-2013. 
cuenta creada por @Doafund ${ }^{8}$ se informa periódicamente de la situación por la que atraviesa cada mes una misma familia:

Doafund 1@doafund). Una nueva familia se integra hoy a Doafund. La familia Sempere Gómez. Conoce su perfil entrando a http://bit.ly/149pRal \#desahucios. 26-06-2013. Tuit.

Doafundt(@doafund). «Tanto yo como mi esposa no queremos otra cosa que trabajar. Hoy corremos el riesgo de perder el piso» Sempere Gómez http://bit. 1y/149pRal. 16-07-2013. Tuit.

Doafund4(@doafund). A la familia Sempere Gómez les quedan 3 días para completar su cuota. Patrocina entrando a http://bit.ly/149pRal o ayuda haciendo RT. 19-07-2013. Tuit.

Doafund (@doafund). Iniciamos la semana con buena noticia. La familia Sempere Gòmez ha completado su cuota. Gracias a todos http://bit.ly/15ALDa9. 22-07-2013. Tuit.

Doafund ((@doafund). A la familia Sempere Gómez les quedan 6 días para completar su cuota. ¿Le ayudas? Patrocina ahora http://bit.ly/1cRSDTj Haz RT. 16-08-2013. Tuit.

Doafund (@@doafund). Buenos días. Estupenda noticia. Los Sempere pagarán la hipoteca este mes gracias a Lucía, Eva y un anónimo. Gracias. http://ow.ly/ p6zFq. 22-09-2013. Tuit.

Doafundt(@doafund).La familia Sempere Gómez consiguió pagar la hipoteca y así lo agradeció a sus patrocinadores http://ow.ly/pcS90 \#patrocinaunafamilia. 25-09-2013. Tuit.

A la dimensión narrativa que subyace en esta secuencia de mensajes cabe superponer una dimensión argumentativa, pues la finalidad última de tal relato es la de promover la colaboración económica desde el perfil con el que esta asociación cuenta en Twitter. Para ello se lleva a cabo la estrategia slice of life, bien conocida en Teoría de la Publicidad (Bassat, 1993). Además, mediante la información periódica sobre cómo es la situación de estos mismos beneficiarios cada mes, desde el perfil @Doafund se ofrece una imagen de transparencia.

Charaudeau (2012: 127) define el discurso propagandístico como «difusión y de circulación del discurso en el espacio público para llegar al mayor número posible de personas (propagare)». Sin embargo, esta consideración del término propaganda en función de su sentido etimológico se nos antoja en cierto modo insuficiente para el estudio de la multiplicidad de objetivos persuasivos subyacentes en los discursos actuales. Especialmente aquellos de

8. Organización dedicada a prestar ayuda promoviendo las donaciones a quienes no pueden afrontar el pago de su hipoteca en España. 
tipo ideológico formulados en el contexto de las redes sociales. Así, etiquetas como \#crisis, \#banca, \#escraches o \#stopdesahucios son claramente ideológicas, ya que remiten a concepciones o visiones del mundo muy diferentes, con las que se ponen de manifiesto los contrastes entre el modelo neoliberal y los modelos económicos y políticos alternativos. De ahí que seamos conscientes de la necesidad de abordar el análisis de este tipo de tuits desde una perspectiva interdisciplinaria, sustentada por ejemplo en la dimensión cognitiva constructivista desde la que sociólogos como Thompson (2001), Castells (2009; 2012), Curran (2011) o Johnston (2011), entre otros, abordan el análisis del discurso del poder.

\section{Tipos de discurso propagandístico}

Entre la tipología de discursos cuya finalidad principal es la de incitar a cometer una determinada acción se encuentra el publicitario. ${ }^{9}$ En nuestro corpus apreciamos una diferencia sustancial respecto al discurso publicitario que prolifera en los medios de comunicación tradicionales. Así, de un modo similar a como sucede en algunas bitácoras, con frecuencia en la red de microblogging Twitter se prescinde de la actividad profesional realizada comúnmente por agencias de publicidad, para convertir a la propia empresa en instancia de enunciación encargada de difundir las bondades de sus productos. No obstante, los recursos de carácter persuasivo no difieren en exceso de los utilizados de manera habitual por la instancia del publicista. Por ejemplo, el gestor del perfil de una compañía en Twitter se sirve de testimonios de clientes satisfechos utilizados a modo de argumentos de autoridad (Robles, 2007) para acreditar las garantías que ofrece un producto,

Habitissimo (@ @habitissimo). «Habitissimo nos ha ayudado en tiempos de \#crisis y estamos muy agradecidos», Pere Marques, cliente @Habitissimohttp:// ow.ly/pBUFz. 08-10-2013. Tuit.

o se presenta como un benefactor capaz de ayudar al alocutario a satisfacer sus necesidades: ${ }^{10}$

9. Cfr. por ejemplo López Eire (1998), Ferraz (2000), Robles y Romero (2010), Adam y Bonhomme (2012) o Janich (2013), entre otros.

10. Puede llamar la atención la intertextualidad de este texto, que guarda gran similitud con los anuncios clasificados difundidos habitualmente en periódicos de información general, algunos 
Cardea Tecnología (@@CardeaT). ¿QUIERE MANTENER SU NEGOCIO A FLOTE DURANTE UNA \#CRISIS? La \#Continuidad administrada protege sus datos y su negocio. http://www.cadea.mx. 07-10-2013. Tuit.

Véase cómo en los mensajes precedentes las empresas utilizan en beneficio propio una etiqueta creada por los internautas fundamentalmente para debatir sobre los efectos de la crisis. Esta práctica podría calificarse como uso «parasitario»-análogo en cierto modo al spam que prolifera en los correos electrónicos- e intrusivo, que se inserta entre la miríada de opiniones que ese hashtag congrega en torno a sí mismo. Más aún si este se ha convertido en trending topic, con lo que el número potencial de destinatarios del tuit de carácter publicitario se verá incrementado exponencialmente.

Un poco más adelante nos detendremos en analizar el discurso mediático. No obstante, merece la pena comentar el siguiente tuit publicado por un medio de comunicación:

Expansion_orbyt 1(@expansion_orbyt).La \#banca dejaría de ingresar 1.137 millones sin suelos hipotecarios http://expansionpro.orbyt.es/2013/06/13/ banca_y_finanzas/1371156600.html .... 13-06-2013. Tuit.

El diario Expansión, dedicado a la difusión de contenidos especializados en el ámbito económico, posee tres perfiles en Twitter: @expansioncom, @ expansionbolsa y@expansion_orbyt.En los tres se publican tuits que recogen los titulares de las informaciones más destacadas de la edición digital de este periódico junto con enlaces que remiten a las propias noticias, con la diferencia de que en la última de estas cuentas el internauta que acceda a dicho enlace será conducido a la sección con la que Expansión cuenta en el quiosco digital multisoporte Orbyt, una plataforma que solo permite consultar sus contenidos previo pago. De forma que el usuario de Twitter que, atraído por el contenido de este mensaje, haga clic en el enlace, podrá leer únicamente el titular y un breve extracto del lead de la noticia. Para acceder al resto de la información tendrá que comprar la edición de Expansión para Orbyt.

Por tanto, tuits como el anterior responden más a una finalidad publicitaria que a la meramente informativa. Especialmente si se edita el titular para convertir una de las lexías que lo conforman en una etiqueta, como sucede en el mensaje antes mencionado con el término \#banca. Esta podría considerarse

de los cuales pueden encontrarse en $<$ http://www.lahistoriadelapublicidad.com $>$. Última consulta: $27-10-2013$. 
también una doble estrategia publicitaria encaminada, por una parte, a otorgar mayor visibilidad a la empresa periodística -incrementándose de manera exponencial si este hashtag llega a convertirse en tema del momento-y, por otra, a seleccionar entre todos los usuarios de Twitter a los interesados en la temática de carácter financiero. Además, los propios consumidores de este tipo de publicidad se convierten en «cómplices» de esta sutil campaña de márquetin al retuitear tanto el titular como el enlace que conduce a la noticia de pago, aunque su propósito sea únicamente manifestar su punto de vista sobre la información recogida:

Mónica Melle (@@monicamelle). Pues q ganen un poco menos....La \#banca dejaría de ingresar 1.137 millones sin suelos hipotecarios http://expansionpro. orbyt.es/2013/06/13/banca_y_finanzas/1371156600.html ... 13-06-2013. Tuit.

Ya Lara (2008) ha puesto de manifiesto cómo la conectividad con las audiencias es una de las principales motivaciones que llevan a los medios a situarse en las redes sociales -cfr. también Helfrich (en prensa)-. De hecho, Johnson (2009) asegura que en un futuro no muy lejano todo gran canal de información será tuiteado. Precisamente una de las funciones que Orihuela (2011) atribuye a Twitter es su uso como plataforma de publicación, lo que ha llevado a numerosos periodistas a servirse de esta red de microblogging para cultivar la relación de proximidad con sus lectores, creando la sensación de que comparten con ellos intereses e inquietudes dentro de una misma comunidad. Por ejemplo, en el siguiente tuit Ramón Lobo -colaborador de El Periódico, InfoLibre y la Cadena Ser- no se limita a dar a conocer mediante un enlace la fórmula creada por un comité de expertos para calcular las pensiones en los próximos años, sino que trata de manifestar a sus seguidores su convicción de que sea como sea dicho cálculo les va a perjudicar:

Ramón Lobo 1(@ramonlobo). Si no entiendes la fórmula del cálculo de las \#pensiones, no preocupes: pase lo que pase, bonanza o crisis, pierdes pic. twitter.com/MDdgWhn2HD. 07-06-2013. Tuit.

Y de esta forma apela a los seguidores de la etiqueta \#pensiones uno de los tertulianos del debate televisivo Al Rojo Vivo, para pedir su colaboración al tiempo que promociona el programa:

Fernando Berlín 1(@radiocable). Venga, echadme una mano estamos en@ DebatAlRojoVivo hablando de las \#pensiones. I¿deas?. 07-06-2013. Tuit. 
Asimismo, como puede apreciarse en el siguiente mensaje del director editorial de Infolibre, algunos periodistas se sirven de los hashtags para anunciar la publicación de columnas de opinión elaboradas por sus colaboradores,

Jesús Maraña (@@jesusmarana). «Los otros escraches», por @manuelrico en \#infolibrehttp://bit.ly/13EcKku \#desahucios\#PAH. 29-03-2013. Tuit.

o incluso para otorgar mayor difusión a sus propios artículos:

Vicente Vallést(@VicenteVallesTV). El \#Príncipe, la \#crisis y los otros... http: //ow.ly/pJ6oW.11-10-2013.Tuit.

Aunque entre las finalidades del discurso mediático se encuentran fundamentalmente la de ofrecer información o interpretar la actualidad noticiosa desde una posición de saber acerca de los asuntos políticos y sociales del mundo que otorga legitimidad a la instancia informativa, creemos que en mensajes como los anteriores impera también un propósito propagandístico. No en vano, los periodistas insertan en sus mensajes una etiqueta que saben que otorgará mayor difusión a su trabajo, haciendo que este sea conocido por una audiencia potencialmente interesada en temas como la crisis, los desahucios o la situación de la banca española. Una práctica similar siguen las empresas periodísticas como El País, que difunde de esta forma la crónica de una de sus corresponsales: ${ }^{11}$

EL PAÍS Política'(@elpais_politica).El PP se queda solo en la aprobación de la nueva ley antidesahucios. Una crónica de @anabeldn. \#desahucioshttp:// politica.elpais.com/politica/2013/04/18/actualidad/1366292843_530574.html .... 18-04-2013. Tuit.

Es cierto que este tuit difiere del de @expansion_orbyt que analizábamos más arriba, pues contiene un enlace que permite acceder a la noticia completa sin necesidad de pagar por consultarla. Además, incita a los interesados en la etiqueta \#desahucios a acceder a la página web del medio de comunicación

11. Aunque véase cómo en el texto no se recoge su nombre, sino el que identifica a su cuenta en Twitter. Tal vez porque, a juzgar por sus más de 25.000 seguidores, se la considera lo suficientemente conocida en esta red social como para mencionar únicamente su nombre de usuario. También podría identificarse este recurso como una muestra de publicidad semiescondida, ya que no conviene olvidar que el nombre de usuario es un elemento multimodal que funciona como enlace, capaz de dirigir a los lectores del tuit directamente al perfil de esta periodista. 
para consultar una crónica cuyo titular ha sido modificado ligeramente, quizás en un intento de llamar la atención de un mayor número de internautas:

«El PP aprueba solo la ley de desahucios tras intentar atraer a algún grupo», Anabel Díez, El Pais, 18-04-2013, disponible en: <http://politica.elpais.com/ politica/2013/04/18/actualidad/1366292843_530574.html>. Última consulta: 24-10-2013.

Y al comparar este otro mensaje difundido por la agencia de noticias Europa Press,

EP_Economía)(@EPEconomia).\#ÚLTIMAHORA. De Guindos limita a 2.000 millones las necesidades adicionales de capital de la \#banca española - http:// goo.gl/TEHDu. 18-06-2013. Tuit.

con el titular de la noticia mencionada -a la que puede accederse directamente mediante el enlace que recoge el tuit-

«De Guindos dice que la banca necesitará 2.000 millones adicionales», Europa Press, 18-06-2013, disponible en: <http://www.europapress.es/economia/finanzas00340/noticia-guindos-limita-2000-millones-necesidades-adicionales-capitalbanca-espanola-20130618122721.html .Última consulta: 24-10-2013.

advertimos cómo el verbo de habla introductor de discurso referido decir ha sido sustituido en Twitter por el verbo limitar, lo que conlleva una interpretación añadida por parte del gestor del perfil desde el que se ha difundido la información en esta red social. ${ }^{12}$ Asimismo, además del hashtag \#banca, se ha escogido el de \#últimahora, quizás en un intento de atraer a otros lectores ávidos de conocer la actualidad. Una estrategia muy utilizada también por otros medios de comunicación, que recurren a esa misma etiqueta de vago contenido referencial, lo que explicaría que esta suela aparecer acompañada por otras que identifican el tema del mensaje de manera más precisa:

20minutos.es1(@20m). \#ultimahora La PAH quiere retirar su ILP contra desahucios porque la propuesta del PP «desvirtúa» el texto \#pah \#desahucios. 18-04-2013. Tuit.

12. Como recuerda Méndez (2000: 150), para ciertos autores -como Palmer (1986) - «existe una modalidad lingüística específica, la citativa, que marca la falta de compromiso del hablante en la verdad de su proposición. Sin embargo, la existencia de una gama tan amplia de verbos de habla introductores de discurso referido es la mejor prueba de que hay interpretación». 
Vamos a centrarnos ahora en el análisis de otro tipo de discurso esencialmente propagandístico: el político. ${ }^{13}$ El uso de Twitter como herramienta de propaganda electoral cobró gran relevancia durante los comicios presidenciales norteamericanos de $2008 .{ }^{14} \mathrm{~A}$ partir de entonces las redes sociales han modificado la forma tradicional de hacer campaña, reduciendo los costes de la comunicación directa con el ciudadano, y modificando las relaciones entre las élites políticas y los electores (Miller, 2008). En España, durante la campaña electoral de noviembre de 2011 Twitter logró la hegemonía de la comunicación política en la Red, en perjuicio de otras redes sociales (Mancera y Pano, 2013). Pero en la actualidad los tuits no solo son utilizados como medios de propaganda política durante los comicios, sino también como instrumento de comunicación habitual entre políticos e internautas. Así, esta red social se ha convertido en una herramienta de gestión de la imagen de los gobernantes -o de aquellos que aspiran a serlo-, muy eficaz para ayudarles a alcanzar el poder y a mantener una comunicación más fluida con los ciudadanos. En nuestro corpus las manifestaciones del discurso político pueden clasificarse en dos grandes grupos. Por una parte se encuentran los mensajes de apoyo hacia las políticas llevadas a cabo por el Gobierno para hacer frente a la crisis. Estos son publicados por líderes del Partido Popular, por los perfiles institucionales del propio partido o de sus delegaciones regionales, así como por organizaciones afines, como Nuevas Generaciones del PP de la Comunidad Valenciana, que en el siguiente mensaje recurre a la etiqueta \#austeridad para alabar la gestión del presidente de dicha comunidad, Alberto Fabra, representante de esta formación:

NNGG C. Valenciana ((@NNGG_CV). \#Austeridad El Consell de@ AlbertoFabra ahorra 2 millones con eficiencia energética en los edificios públicos http://www.larazon.es/noticia/7951-el-consell-quiere-bajar-un-22-5el-gasto-de-luz-de-los-hospitales .... 26-11-2013. Tuit.

Por otra parte, muy distinta es la perspectiva adoptada por los partidos y por los políticos en la oposición, que recurren a Twitter para criticar tanto al Gobierno como a quienes atribuyen la responsabilidad de la crisis. En su mayoría, los tuits de este corpus pueden caracterizarse como discurso populista del tipo manipulación débil que, según Charaudeau (2012: 132), se presta

13. La bibliografía en español dedicada a analizar este tipo de discurso es muy numerosa. Cfr. por ejemplo Coseriu, 1994; Fernández Lagunilla, 1999a y 1999b; Van Dijk, 2002; Blas Arroyo, 2011, entre otros.

14. Cfr. Cornfield (2008) o Gutiérrez-Rubí (2008). 
especialmente bien para contextos de crisis social. Igualmente representativos de este contexto son los actos de (auto)defensa y justificación. Entre los primeros destacan aquellos tuits con los que un dirigente pretende poner de relieve gestiones positivas llevadas a cabo por él mismo en el pasado - de ahí el uso constante del verbo recordar-, con el fin de presentarse como el único que combate la crisis con medidas eficaces:

Partido Popular'(@PPopular). Recordamos que el Gobierno de @marianorajoy ha sido el primero en legislar contra los \#Desahucios. 05-06-2013. Tuit.

Compárese también el mensaje en forma de testimonio personal -os dejodel alcalde de Gandía, Arturo Torró, en el que recurre a términos como ahorrar y austeridad, que en momentos de crisis otorgan a su gestión connotaciones positivas,

Arturo Torró (@@arturotorro). Os dejo la noticia de Canal 9 sobre mi decisión de renunciar al sueldo como alcalde de \#Gandia para ahorrar \#austeridadhttp:// ow.ly/cILoO. 03-09-2013. Tuit.

y este otro con el que UPyD Asturias anuncia la puesta en práctica de una medida de ahorro con la que se felicita indirectamente, mostrando que ha sido iniciativa suya:

UPyD Asturias 1(@UPyDAsturias). Los portavoces de la Junta General del Principado renuncian a los coches oficiales a iniciativa de @UPyD - http:// www.asturiasmagenta.es/administraciones-publicas/los-portavoces-de-lajunta-general-del-principado-renuncian-a-los-coches-oficiales-a-iniciativa-deupyd/ ...\#austeridad. 04-05-2012. Tuit.

En los ejemplos de nuestro corpus se incluyen también hiperenlaces que remiten a recursos multimodales de distinto tipo -fotografías, vídeos, documentos o mensajes publicados en otras redes sociales, como Facebook-, que pretenden exhibirse tanto como (auto)justificación como prueba de acusación, según la autoría del mensaje. Asimismo, es frecuente que el hilo argumentativo se refuerce con estadísticas como la utilizada por el exalcalde socialista de San Sebastián, Odón Elorza, para dañar la imagen positiva (Brown y Levinson, 1978) del adversario político:

Odón Elorza'(@odonelorza2011).STOP a las políticas d \#austeridad y recortes sociales. España tendría un $40 \%$ de pobres dentro de diez años. http://www. 
diariovasco.com/rc/20121213/mas-actualidad/sociedad/poblacion-espanolasera-pobre-201212131659.html .... 17-12-2012. Tuit.

Por último, entre los tipos de discurso propagandístico identificados por Charaudeau (2012) se encuentra el promocional, con el que se persigue prevenir una calamidad o persuadir a la población para que se comporte de una determinada manera o adopte ciertos hábitos. En nuestro corpus abundan los mensajes en los que organizaciones y plataformas de reivindicación dirigen apelaciones a los usuarios de Twitter instándolos, por ejemplo, a acudir a una manifestación:

Juventud SIN Futuro ‘(@juventudsin). \#YaDeberíasSaberQue el viernes hay un nuevo \#escrache en Madrid. 19H en la glorieta del metro de Rubén Darío. ¡Vente! pic.twitter.com/JIFqFxVpPU. 24-04-2013. Tuit.

En el mensaje precedente Juventud Sin Futuro (JSF) ${ }^{15}$ se sirve de la segunda persona del singular para apelar directamente a cada internauta, instándole mediante un imperativo y un pronombre personal en posición enclítica a que acuda a una manifestación frente al domicilio de un gobernante para reprobar su comportamiento. De ahí que recurra al hashtag \#escrache. Llama además la atención el uso de la etiqueta \#YaDeberíasSaberQue para presentar el contenido del tuit como información consabida por el ciudadano, al que implícitamente se le atribuye el deber moral de estar al tanto de esta acción reivindicativa. Asimismo, encontramos una nueva muestra de comunicación multimodal en el enlace que remite a una fotografía con los datos y el eslogan de la convocatoria, una estrategia más de carácter persuasivo.

También en el siguiente tuit la etiqueta \#escrache es utilizada por la organización Democracia Real Ya Madrid (DRYMadrid) ${ }^{16}$ para incitar a la población a manifestarse. Si bien en este caso el hashtag forma parte del propio lema de la convocatoria $-«$ De la indignación a la rebelión: Escrache al sistema»- ${ }^{17}$ y el

15. Un colectivo surgido en abril de 2011 para mostrar la situación de precariedad de la juventud en el ámbito laboral. Cfr. <http://juventudsinfuturo.net/sample-page/>. Última consulta: $25-$ 10-2013.

16. Cfr. $<\mathrm{http}: / /$ madrid.democraciarealya.es/contacto/> para conocer su ideario. Última consulta: 25-10-2013.

17. Cfr. por ejemplo la noticia que informaba sobre esta convocatoria en el diario El País: «Bajo el lema: «De la indignación a la rebelión: Escrache al sistema»», El País, 11-05-2013, disponible en: <http://ccaa.elpais.com/ccaa/2013/05/11/album/1368288064_397106.html\#13 68288064_397106_1368383142>. Última consulta: 25-10-2013. 
enlace no remite a una imagen, sino a una página web en la que se proporcionan los datos necesarios para poder acudir a la convocatoria:

DRYmadrid1(@DRYmadrid). De la Indignación a la rebelión. \#Escrache al sistema. http://mayo2013.tomalaplaza.net/ \#Plántate15M. 03-05-2013. Tuit.

En este sentido véase cómo, al contrario de lo que sucedía en el texto anterior -en el que se aportaban los datos fundamentales sobre el acto de protesta-, este mensaje tiene un carácter exclusivamente persuasivo. Algo que puede apreciarse además en el imperativo de la etiqueta con la que concluye, un eslogan en el que sus lexías se presentan fusionadas: \#Plántate15M.

En algunos de estos textos la incitación a participar en un escrache no procede de los perfiles de organizaciones o movimientos sociales, sino de usuarios individuales de Twitter que se sirven incluso de insultos para tratar de persuadir a otros internautas:

CarlosNavarroMerino 4(@CNavarroMerino). Hay que hacer \#Escrache 24 horas al día hasta que dimita a la incompetente y déspota @mdcospedal por su insultante y temeraria actitud. RT. 18-04-2013. Tuit.

Con el uso de los adjetivos calificativos incompetente, déspota, insultante y temeraria, el autor del mensaje realiza actos de amenaza a la imagen (Brown y Levinson, 1978) de una persona de relevancia pública, como es María Dolores de Cospedal, secretaria general del Partido Popular. Sin embargo, no alude a ella haciendo uso de su nombre propio, sino del perfil con el que esta gobernante cuenta en Twitter, lo que convierte la actividad promovida en un acto de habla amenazante. ${ }^{18}$ Además, mediante la inclusión de la abreviatura de retuiteo (RT) se insta a los lectores del tuit a reenviarlo para que sus ataques ad hominem cuenten con una mayor repercusión.

Los ejemplos de este tipo, en los que se hace uso de la agresividad e incluso de la violencia verbal podrían multiplicarse con facilidad. Sin embargo, Twitter también puede ser utilizado como herramienta para difundir valores positivos como el respeto a los animales. Por ejemplo, el siguiente mensaje

18. El uso del nombre del perfil de Twitter de M. ${ }^{a}$ D. de Cospedal, en lugar de su nombre real, no solo es una forma de ahorrar algunos caracteres, sino también una manera de hacer que el mensaje aparezca recogido en la sección Menciones. Este es un apartado especial en la cuenta de un usuario que permite ver fácilmente qué personas han mencionado, por las razones que sean, su nick en esta red social. En este sentido la amenaza es más directa, pues el emisor tiene cierta garantía de que el mensaje llegará a su alocutario. 
recurre a un conocido modismo que conlleva implícitamente la personificación de los animales de compañía. Le sigue un enunciado exclamativo con el que se insta a no «traicionarles»-de nuevo, un término que «humaniza» a los referentes-, y otro en modalidad declarativa que destaca el tema principal de una noticia disponible a través de un enlace que se adjunta al final del propio tuit:

Advantix ${ }^{\circledR}$ España ((@Advantix). Si donde comen 2, comen 3, ¡no los traiciones! La \#crisis agudiza el abandono de \#perros. Evítalo, sé responsable: http://ow.ly/pc5Y7. 01-08-2012.Tuit.

En principio podría pensarse que el contenido de este texto es promocional, pues mediante las formas imperativas evitalo o sé responsable se pretende inscribir a la instancia de recepción en una ética de responsabilidad. Sin embargo, su finalidad es esencialmente publicitaria. Así, dicho mensaje ha sido difundido por el perfil comercial de Advantix ${ }^{\circledR}$ España. ${ }^{19}$ Por tanto, aunque su contenido sea informativo - pues difunde una noticia publicada ese mismo día en el diario ElEconomista.es-, y adopte fórmulas recurrentes en el discurso promocional, en realidad estamos ante una estrategia publicitaria común en esta red social. Y es que resulta frecuente que desde la cuenta de usuario de una empresa comercial se envíen tuits que permiten asociar la imagen de la marca con valores positivos. Además, este tipo de perfiles ofrece a sus seguidores noticias que los mantiene informados sobre la temática que más les interesa. Por otra parte, el texto analizado responde también a la necesidad inherente en cualquier cuenta de usuario de Twitter de mantener una presencia realmente activa. Así, con el objetivo de no provocar un rechazo en el alocutario con continuos mensajes publicitarios, se recurre a la difusión de noticias que se encuentran en su horizonte de interés, y que proporcionan por tanto un valor añadido al perfil de la empresa -y por ende, a su imagen de marca-. Por último, mediante el uso de etiquetas como las que aparecen en este tuit, (a)Advantix pretende difundir su mensaje no solo entre los internautas interesados en el cuidado de los canes -\#perros-, sino también entre aquellas noticias que contengan el hashtag \#crisis. De esta manera un solo mensaje se sitúa en la confluencia de dos coordenadas muy diferentes, una vinculada al campo semántico de los intereses de la empresa, y otra a la actualidad mediática. Por tanto, creemos que Twitter ha modificado en gran medida las condiciones del contrato de comunicación (Charaudeau, 1992) por el que suelen regirse los discursos propagandísticos.

19. Un producto creado por los laboratorios Bayer para combatir la leishmaniasis canina. 
En la siguiente tabla mostramos el número de tuits que poseen contenidos de carácter propagandístico, clasificándolos en función de los cuatro tipos de discurso que hemos identificado en las páginas precedentes:

\begin{tabular}{|c|c|c|c|c|c|}
\hline \multicolumn{6}{|c|}{ CÓMPUTO DE TUITS } \\
\hline & \multicolumn{4}{|c|}{ Con contenido propagandístico } & \multirow{2}{*}{$\begin{array}{l}\text { Sin contenido } \\
\text { propagandístico }\end{array}$} \\
\hline Etiquetas & Publicitario & Mediático & Político & Promocional & \\
\hline \#austeridad & 2 & 31 & 23 & 1 & 43 \\
\hline \#banca & 14 & 48 & 4 & 3 & 31 \\
\hline \#crisis & 5 & 37 & 3 & 7 & 48 \\
\hline $\begin{array}{l}\text { \#crisisecono- } \\
\text { mica }\end{array}$ & 4 & 48 & 11 & 3 & 34 \\
\hline \#desahucios & 4 & 55 & 4 & 14 & 23 \\
\hline $\begin{array}{l}\text { \#economis- } \\
\text { tasfrenteala- } \\
\text { crisis }\end{array}$ & 30 & 43 & 5 & 2 & 20 \\
\hline \#EPA & 10 & 15 & 4 & 5 & 66 \\
\hline \#escraches & 2 & 24 & 16 & 21 & 37 \\
\hline \#euco & 0 & 29 & 11 & 7 & 53 \\
\hline \#Eurogrupo & 2 & 75 & 1 & 1 & 21 \\
\hline \#pah & 5 & 34 & 12 & 8 & 41 \\
\hline \#paro & 7 & 57 & 6 & 6 & 24 \\
\hline \#pensiones & 9 & 62 & 6 & 2 & 21 \\
\hline $\begin{array}{l}\text { \#recapitaliza- } \\
\text { ción }\end{array}$ & 13 & 64 & 6 & 0 & 17 \\
\hline \#recesión & 6 & 68 & 3 & 2 & 21 \\
\hline \#rescates & 7 & 43 & 1 & 0 & 49 \\
\hline $\begin{array}{l}\text { \#stopdesahu- } \\
\text { cios }\end{array}$ & 3 & 27 & 6 & 36 & 28 \\
\hline$\# 15 \mathrm{M}$ & 1 & 13 & 7 & 12 & 67 \\
\hline & $\begin{array}{c}124 \\
(10,72 \%)\end{array}$ & $\begin{array}{c}773 \\
(66,86 \%) \\
\end{array}$ & $\begin{array}{c}129 \\
(11,15 \%)\end{array}$ & $\begin{array}{c}130 \\
(11,24 \%)\end{array}$ & \multirow{2}{*}{$644(35,77 \%)$} \\
\hline & \multicolumn{4}{|c|}{$1156(64,22 \%)$} & \\
\hline \multicolumn{6}{|c|}{ Número total de tuits: 1800} \\
\hline
\end{tabular}


Como puede apreciarse, la mayor parte de los mensajes que conforman nuestro corpus analítico ostenta carácter propagandístico -el 64,22 \%-, y apenas un tercio de ellos -el 35,77\%-carece de este tipo de contenidos. Estos últimos suelen contener valoraciones de los internautas acerca de aspectos relacionados con la crisis, o informaciones sobre cuestiones de la actualidad noticiosa vinculadas con la etiqueta mencionada en cada caso. Por tanto, dichos textos nada tienen que ver con el concepto de propaganda que hemos presentado al inicio de esta investigación.

Por otra parte, de los cuatro tipos de discurso propagandístico que identificábamos, el más recurrente en los tuits estudiados es el que hemos denominado mediático, con el que las empresas periodísticas aprovechan su presencia en Twitter para difundir entre los seguidores de esta red social sus contenidos, instándolos a acceder al enlace de una determinada noticia publicada en su página web, o con el que los propios comunicadores publicitan los contenidos elaborados por ellos mismos. Estos mensajes constituyen el 66,86\% del total de tuits con contenido propagandístico, mientras que las otras categorías discursivas identificadas tienen una representatividad mucho menor. Así, el discurso promocional podemos localizarlo en el 11,24\% de los textos, el político en el $11,15 \%$ y el publicitario apenas en el 10,72\%.

De las dieciocho etiquetas en función de las cuales hemos recopilado los 1800 tuits que analizamos, las utilizadas de manera más frecuente por periodistas y medios de comunicación para hacer propaganda de sus contenidos son \#Eurogrupo (75 tuits representativos del discurso mediático), \#recesión (68), \#recapitalización (64) y \#pensiones (62). Estas son aprovechadas por las empresas periodísticas para difundir noticias en relación con las decisiones adoptadas por los ministros de Economía y Finanzas de los países que constituyen la denominada «Zona Euro», o para informar acerca de las medidas adoptadas por España para superar el descenso en su actividad productiva y la reforma de las pensiones. Por otra parte, nada extraña que \#stopdesahucios (36 tuits característicos del discurso promocional), \#escraches (21) y \#desahucios (14) sean los hashtags más utilizados por los internautas para difundir contenidos de carácter promocional, con los que instan a la movilización con el fin de paralizar la expulsión de sus viviendas de aquellos que no pueden pagar la hipoteca, o a manifestarse frente al domicilio de los líderes políticos para denunciar su gestión de la crisis. Lógicamente, el significado de la etiqueta \#escraches hace que sea también una de las más utilizadas en la propaganda política (16 tuits), si bien la más recurrente en los discursos de este tipo que conforman nuestro corpus es \#austeridad (23). Por último, es \#economistasfrentealacrisis el hashtag más representativo del discurso publicitario (30), pues es aprovechado 
por los miembros de dicha asociación de economistas para recomendar a los seguidores de esta red social que adquieran los libros sobre la crisis publicados por este grupo de expertos.

\section{Conclusiones}

Según Castells (1996) nos encontramos en una sociedad red que se caracteriza por un estado mental colectivo en el que las conciencias de los ciudadanos son redes neuronales que interactúan con otras mentes y con otras redes del entorno social y natural. De hecho, las redes sociales operan como un sistema sináptico (Orihuela, 2011) que facilita la organización espontánea de sus participantes. Ya Negroponte (1995) advirtió del inmenso potencial que poseen las redes sociales para la democracia, debido a que la hiperconectividad que promueven permite construir conglomerados de relaciones, y descubrir patrones de pensamiento comunes. Esto se hace especialmente patente en los mensajes publicados en Twitter, gracias a los que el internauta logra un nivel elevado de presencia ciberespacial (Zhao y Rosson, 2009) o, como explica Yus (2010: 161), «una sensación de "estar ahí" [que permite] obtener otro nivel de conexión con los amigos y el mundo en general».

En primer lugar, esta presencia constante que permite la publicación diaria de tuits resulta especialmente beneficiosa para las empresas, pues les ofrece la oportunidad de difundir las bondades de sus productos en esta red social (Schaefer, 2012). Con este fin intentan atraer la atención de potenciales clientes incluyendo en sus mensajes etiquetas que pueden llegar a convertirse en temas del momento debido al alto interés social que generan -como son, por ejemplo, \#crisis, \#pensiones o \#paro-. La inserción de este tipo de hashtags no solo otorga mayor repercusión a sus mensajes, sino que ofrece un valor añadido a su imagen de marca, al mostrarse como compañías al tanto de las principales preocupaciones de sus clientes en momentos de dificultades económicas.

Un tipo especial de compañías ha suscitado también nuestro interés: las empresas de comunicación. Tanto para estas como para los profesionales que en ellas trabajan, la interacción con su audiencia potencial en Twitter permite otorgar mayor difusión a sus productos periodísticos o audiovisuales. Además, para Charaudeau (2012) el discurso mediático es esencialmente propagandístico, ya que la instancia de enunciación persigue hacer saber al alocutario, basándose en la legitimidad que le confiere su posición de conocedor de la actualidad noticiosa. Esto lleva al perfil de un periodista o al gestionado por 
un medio de comunicación a la publicación constante de mensajes con los que demuestra que se encuentra permanentemente al tanto de las últimas noticias. Lo que por añadidura puede lograr atraer a la página web del medio a internautas deseosos de conocer la información de última hora, incrementando de esta forma su número de visitas. Como en el caso anterior, el uso de etiquetas vinculadas con aspectos que guardan relación con la crisis económica incrementa el interés de los ciudadanos por sus mensajes. Según hemos podido apreciar en nuestro análisis, muchos de ellos llegan incluso a retuitear sus textos, lo que actúa como un refuerzo añadido de la actividad propagandística del propio medio de comunicación.

También para las formaciones y los líderes políticos -siempre deseosos de mostrarse en «primera línea» del debate público- Twitter ofrece la oportunidad de interactuar de forma directa con internautas ante los que no dudan en solicitar su voto, y de manifestar sus puntos de vista formulando incluso actos de amenaza a la imagen de sus principales oponentes. Con frecuencia, para reforzar su argumentación se sirven de recursos multimodales de distinto tipo, y de etiquetas como \#austeridad, con las que ensalzan sus iniciativas o sus gestiones en el Gobierno para hacer frente a la crisis.

Por último, organizaciones y plataformas de reivindicación creadas para luchar contra la crisis formulan desde sus perfiles en esta red social discursos promocionales con los que tratan de incitar a los ciudadanos a desarrollar conductas solidarias o a acudir a distintas manifestaciones. Para ello recurren también a etiquetas en las que sintetizan eslóganes como \#Plántate15M o \#escrachealsistema.

Sabido es el sentido negativo que el uso cotidiano otorga a la noción de propaganda, ya que con frecuencia se concibe como un sinónimo de manipulación -o «comunicación estratégica», de acuerdo con el marco teórico de Habermas (1984 [1989]) - . Esto es algo que hemos podido apreciar en nuestro corpus, especialmente en los tuits de carácter político, que tratan en su mayoría de perpetuar las estructuras de poder vigentes.

Sin embargo, son muchos los individuos y los grupos que se sirven de manera sistemática de su cuenta de Twitter para «construir» un marco cognitivo -en el sentido de Lakoff (2007) - distinto al hegemónico. De esta forma intentan contrarrestar los mensajes sobre la crisis difundidos tanto por la Troika como por el Gobierno español. Así, frente al marco metafórico de «un país, una familia»-al que corresponden consideraciones como la de que los españoles han vivido por encima de sus posibilidades, o la de que es necesario «apretarse el cinturón»-, los miembros de ATTAC, Equo, AI, Juventud Rebel, DRY u Oxfam, entre otros, aprovechan su perfil en esta red social para 
la difusión de una contra-argumentación respecto a tal interpretación de la crisis. Esto podría considerarse una muestra de lo que ya Laclau y Mouffe (1987: 213) denominaban "estrategia de construcción de un nuevo orden», vinculada con intentos de «instituir puntos nodales diferentes, desde los cuales puede procederse a una reconstrucción positiva distinta del tejido social». No en vano, para Castells (2012: 233) los movimientos sociales en red son «nuevas formas de movimientos democráticos [...] que están reconstruyendo la esfera pública en el espacio de autonomía creado en torno a la interacción entre sitios locales y redes de Internet». Sin embargo, el medio no es el mensaje. Ni siquiera un medio de extraordinaria difusión, como es Internet $\mathrm{y}$, en particular, una red social del alcance de Twitter. Por eso tampoco debe olvidarse que la forma de conexión entre los individuos es multimodal, y que tal interacción abarca tanto redes online como offline, ya existentes en los medios de comunicación y en la sociedad en general. De ahí esa estrecha vinculación que los discursos mediáticos, políticos y promocionales de nuestro corpus guardan en ocasiones con los publicitarios. Tal vez porque todos ellos se sirven de lo que podríamos denominar una retórica de la persuasión en Twitter. Esta se fundamenta en dos coordenadas básicas: el perfil de los usuarios y los hashtags que se utilizan. Podríamos decir que la mayoría de las cuentas que hemos analizado en nuestro corpus constan de un doble componente. Por una parte se encuentra el nombre de usuario y el avatar que lo identifica, que puede ser más o menos corporativo. Por otra, el contenido discursivo desarrollado por el gestor de este perfil a lo largo del tiempo, que responde a dos objetivos muy diferentes: el primero de ellos es el de crear, desarrollar y consolidar una imagen positiva; y el segundo consiste en ofrecer un canal de comunicación especializado que permita atraer al mayor número de seguidores posibles. Asimismo, la segunda coordenada que hemos mencionado anteriormente la constituyen las etiquetas, cuya función no es solo la de facilitar la clasificación de contenidos por su temática, sino también la de crear una red de mensajes, y por añadidura de usuarios que publican, leen y contestan a esos mensajes, llegando incluso a retuitearlos o a conectarlos a su vez con otros hashtags. Por tanto, el éxito de un perfil creado con una finalidad propagandística depende en gran medida del buen uso que se haga del singular arte de la persuasión que impera en Twitter. 


\section{Referencias bibliográficas}

Adam, J. M.; M. Bonhomme (2012): L'argumentation publicitaire. Rhétorique de l'éloge et de la persuasion, París, Armand Colin.

Asociación de Academias De La Lengua Española (2010): Diccionario de americanismos, Madrid, Santillana.

BASSAT, L. (1993): El libro rojo de la publicidad: ideas que mueven montañas, Barcelona, Folio.

Blas Arroyo, J. L. (2011): Políticos en conflicto: una aproximación pragmáticodiscursiva al debate electoral cara a cara, Berna, Peter Lang.

Brown, P.; S. C. Levinson (1978): Politeness: Some Universals in Language Usage, Cambridge, Cambridge University Press.

Castells, M. (1996): La era de la información: la sociedad red, Madrid, Alianza.

- (2009): Comunicación y poder, Madrid, Alianza.

- (2012): Redes de indignación y de esperanza, Madrid, Alianza.

Charaudeau, P. (1992): Grammaire du sens et de l'expression, París, Hachette.

- (2012): «El discurso de la propaganda. Un intento de tipologización» en SHIRO, M.; P. CHARAUDEAU; L. GRANATO (eds.) (2012): Los géneros discursivos desde múltiples perspectivas: teorías y análisis, Madrid / Frankfurt, Iberoamericana / Vervuert. 125-138.

Cornfield, M. (2008): «Yes, It Did Make A Difference», Taking Note. $<$ http://takingnote.tcf.org/2008/06/yes-it-did-make.html>, [28-10-2013].

CoserIU, E. (1994): «Lenguaje y política», en KONIECKI, D. (ed.) (1994): Politica, lengua y nación, Madrid, Fundación Friedrich Ebert. 11-32.

Curran, J. (2011): Media and Democracy, Londres, Routledge.

Fernández Lagunilla, M. (1999 a): La lengua en la comunicación política I: el discurso del poder, Madrid, Arco Libros.

- (1999b): La lengua en la comunicación política II: la palabra del poder, Madrid, Arco Libros.

Ferraz Martínez, A. (2000): El lenguaje de la publicidad, Madrid, Arco Libros.

FUNDÉU (2013): <http://www.fundeu.es/recomendacion/escrache-y-escracharterminos-adecuados/ $>$, [ 26-10-2013].

GutiérRez-Rubí, A. (2008): «Lecciones de la campaña de Obama», Revista Fundació Rafael Campalans, 16: 75-82. <http://www.gutierrez-rubi. es/2008/10/28/lecciones-de-la-campana-de-obama/>, [28-10-2013]. 
Habermas, J. (1984 [1989]): Teoría de la acción comunicativa. Complementos y estudios previos, Madrid, Cátedra.

Helfrich, U. (en prensa): «Tuits al director - ¿desarrollo de un nuevo género en la prensa hispánica?», en BürKI, Y.; H. BARTSCH (eds.): Procesos de transmisión, mediación y transformación en la prensa ayer y hoy, London, Támesis.

JANich, N. (2013): Werbesprache. Ein Arbeitsbuch, Tübingen, Narr.

Johnson, S. (2009): «How Twitter Will Change the Way We Live», Time, 0506-2009. <http://www.time.com/time/printout/0,8816,1902604,00.html>, [ 28-10-2013].

Johnston, H. (2011): States and Social Movements, Cambridge, Polity Press.

LaClaU, E.; C. Mouffe (1987): Hegemonía y estrategia socialista. Hacia una radicalización de la democracia, Madrid, Siglo XXI.

LAкоғF, G. (2007): No pienses en un elefante: lenguaje y debate politico, Madrid, Complutense.

LARA, T. (2008): «La nueva esfera pública. Los medios de comunicación como redes sociales», Telos, 76. <http://sociedadinformacion.fundacion. telefonica.com/telos/articulocuaderno.asp@idarticulo=9\&rev=76.htm>, [ 28-10-2013].

López Eire, A. (1998): La retórica en la publicidad, Madrid, Arco Libros.

Mancera Rueda, A.; A. Pano Alamán (2013): El discurso político en Twitter, Barcelona, Anthropos.

Méndez García De Paredes, E. (2000): «La literalidad de la cita en los textos periodísticos», Revista española de lingüística, 30: 147-168.

MennA, L. (2012): «Nuevas formas de significación en red: el uso de las \#etiquetas en el movimiento 15M», Estudios de Lingüistica del Español, 34: 1-61.

Miller, C.C. (2008): «How Obama's Internet Campaign Changed Politics», The New York Times, 7 November. <http://bits.blogs.nytimes.com/2008/11/07/ how-obamas-internet-campaign-change-politics/?scp=1\&sq=How $\% 20$ Obama \%E2\%80\%99s\%20Internet\%20Campaign \%20Changed $\% 20$ Politics\&st $=$ cse $>$, [ 28-10-2013].

Negroponte, N. (1995): Being Digital, Nueva York, Knopf.

Orinuela, J. L. (2011): Mundo Twitter, Barcelona, Alienta.

Palmer, F. R. (1986): Mood and Modality, Cambridge, Cambridge University Press.

Real Academia Española (2001): Diccionario de la lengua española, Madrid, Espasa Calpe. 
Robles Ávila, S. (2007): «Los argumentos de la publicidad», Español Actual, 87: 77-110.

Robles Ávila, S.; M. V. Romero Gualda (2010): Publicidad y lengua española. Un estudio por sectores, Sevilla, Comunicación Social.

SchaEfER, M. W. (2012): The Tao of Twitter, Nueva York, McGraw-Hill.

Thompson, J. (2001): El escándalo político: poder y visibilidad en la era de los medios de comunicación, Barcelona, Paidós.

VAN DiJK, T. (2002): «Political Discourse and Ideology», en LoRda, C.; C. Ubaldina; M. Ribas (eds.) (2002): Anàlisi del discurs polític, Barcelona, IULA. 115-134.

Yus Ramos, F. (2010): Ciberpragmática 2.0. Nuevos usos del lenguaje en Internet, Barcelona, Ariel.

Zappavigna, M. (2011): «Ambient Affiliation: a Linguistic Perspective on Twitter», New Media Society, 13 (5): 788-806.

Zhao, D.; M. B. Rosson (2009): «How and Why People Twitter: The Role that Micro-blogging Plays in Informal Communication at Work» in TEASley, S. D., E. C. Havn, W. Prinz, W. G. Lutters (eds.), Proceedings of the ACM 2009 International Conference on Supporting Group Work, Universität Trier, Trier. 243-252. 